\title{
Pregnancy in non-communicating rudimentary horn
}

\author{
Ram Kanwar Deora, Preeti Chawla*, Nikhila G. Shetty
}

Department of Obstetrics and Gynecology, Dr. S N Medical College, Jodhpur, Rajasthan, India

Received: 13 February 2017

Revised: 08 March 2017

Accepted: 09 March 2017

\author{
*Correspondence: \\ Dr. Preeti Chawla, \\ E-mail: preeti.chawla67@gmail.com
}

Copyright: $($ the author(s), publisher and licensee Medip Academy. This is an open-access article distributed under the terms of the Creative Commons Attribution Non-Commercial License, which permits unrestricted non-commercial use, distribution, and reproduction in any medium, provided the original work is properly cited.

\begin{abstract}
A 25-year old G3P2L2 presented to casuality of OBG Dept, Ummaid Hospital, Jodhpur with5 months amenorrhea and bleeding per vaginum for last 5 days associated with abdominal pain. On per abdomen examination, a mass arising from pelvis corresponding to the size of a 16 weeks pregnancy was seen. A repeat ultrasound was performed in our hospital and the findings were - normally visualised uterus with a gestational sac with thin myometrium rim seen on right side with single dead fetus of gestational age 14 weeks 3 days, pregnancy in rudimentary horn, bicornuate uterus with pregnancy in right horn. Patient was counselled and prepared for laparotomy which was performed under general anesthesia. Intra -operative findings were normal sized uterus, right sided rudimentary horn pregnancy was seen. Both tubes and ovaries were normal. Hence, right sided rudimentary horn excision along with ipsilateral salpingo - oophorectomy was planned and done by clamping and cutting. Hemostasis was achieved. There was no communication between the rudimentary horn and the main uterus. The estimated blood loss was $200 \mathrm{ml}$.
\end{abstract}

Keywords: Mullerian duct, Rudimentary horn, Trans-peritoneal migration

\section{INTRODUCTION}

Rudimentary horn pregnancy is a rare obstetric entity and its diagnosis and management is important as it carries grave consequences to both mother and foetus. Unicornuate uterus with a rudimentary horn is a rare mullerian anomaly that has a high incidence of obstetric complications that include ectopic pregnancy in the rudimentary horn. ${ }^{1}$ Pregnancy in non-communicating rudimentary horn is possible by trans-peritoneal migration of sperm or fertilized ovum. It occurs in approximately 1 of every 76,000 pregnancies. The risk of uterine rupture is $50-90 \%$, with most ruptures (approximately 80\%) occurring by the end of the second trimester. ${ }^{1-3}$

We report our experience in diagnosing and managing a case of fetal death in a rudimentary horn which was missed on routine malformation scan.

\section{CASE REPORT}

A 25-year old G3P2L2 presented to casuality of OBG Dept, Ummaid Hospital, Jodhpur with chief complaints of 5 months amenorrhea and bleeding per vaginum for last 5 days. Bleeding was associated with abdominal pain. Her both previous deliveries were by LSCS at term. She did not have any history of intraoperative or post operative or wound complications in her past pregnancy. In her present pregnancy, she conceived spontaneously.

On clinical examination, she was found to be hemodynamically stable with no pallor or tachycardia. On per abdomen examination, a mass arising from pelvis corresponding to the size of a 16 weeks pregnancy was seen. No guarding, rigidity, and tenderness were noted. On per speculum examination, cervix was tubular, posterior with closed external os without any ballooning up of cervix. On per vaginal examination, cervix was firm, $2.5 \mathrm{~cm}$ long, posterior and the os was closed. There 
was no adnexal mass felt and the uterus was not displaced to either side. There was no evidence of active bleeding through os.

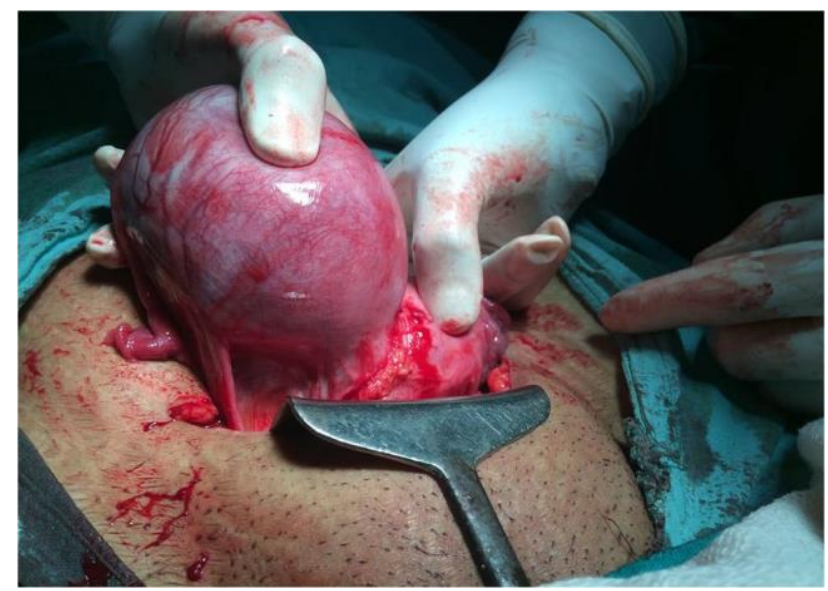

Figure 1: Pregnant rudimentary horn (in the hand of the assistant) still attached to the main horn. The right ovarian ligament and tube have been clamped and cut from the rudimentary horn.

Patient was hospitalized and preoperative investigations including complete hemogram, renal and liver function tests were sent. All investigations were within normal limits. Patient had ultrasound reports from her hometown with impression of $15 \mathrm{wks}$ intrauterine IUD. A repeat ultrasound was performed in our hospital and the findings were

- Normally visualized uterus with a gestational sac with thin myometrium rim seen on right side with single dead fetus of gestational age 14 weeks 3 days,

- Pregnancy in rudimentary horn,

- Bicornuate uterus with pregnancy in right horn.

Patient was counselled and prepared for laparotomy which was performed under general anesthesia.

\section{Intra-operative findings}

Normal sized uterus, right sided rudimentary horn pregnancy was seen. Both tubes and ovaries were normal. Hence right sided rudimentary horn excision along with ipsilateral salpingo oophorectomy was planned and done by clamping and cutting. Hemostasis was achieved. There was no communication between the rudimentary horn and the main uterus. The estimated blood loss was $200 \mathrm{ml}$.

Postoperative recovery was uneventful. She was counselled on family planning and given a referral to the family planning clinic. She was also educated on the need for antenatal care and elective caeserian section for any future pregnancy. Patient was discharged on $6^{\text {th }}$ day postoperatively after stitch removal. Histopathology report findings were consistent with ectopic (uterine horn) gestation.

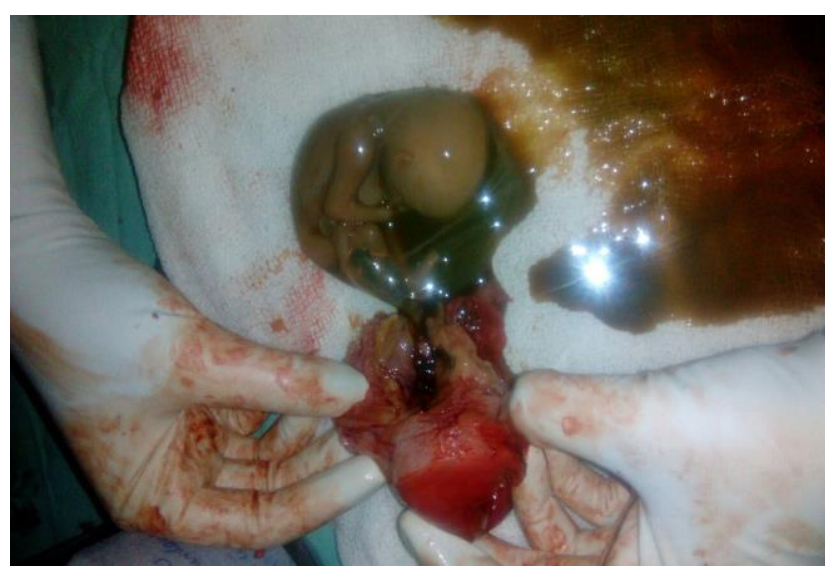

Figure 2: Sectioned rudimentary horn showing conceptus in intact membranes.

\section{DISCUSSION}

Unicornuate uterus with a rudimentary horn is a mullerian duct malformation. Mullerian duct malformations have an incidence of $4.3 \%$ in the general population while that of unicornuate uterus is about $0.4 \% .^{2}$ Rudimentary horn pregnancy occurs in approximately $1 / 76000$ to $1 / 150000$ pregnancies. ${ }^{3,4}$ In the past, majority of cases were diagnosed after rupture of the rudimentary horn. However, with the advent of ultrasound scan, CT scan, MRI, and laparoscopy, the diagnosis is more often being made before rupture. There have even been reports of first trimester prerupture diagnosis of rudimentary horn pregnancy. ${ }^{5}$ In the case of Madam CA, the diagnosis was not suspected on ultrasound scan therefore induction of labour was attempted. Even when the diagnosis was suspected clinically, other methods of confirmation such as CT scan and MRI could not be used because they were not readily available.

Rudimentary horn pregnancy has a relatively small incidence, though the risk of serious maternal morbidity and mortality is high. Early prerupture diagnosis is therefore very important.

The following criteria have been suggested by Tsafri et al for sonographic diagnosis of rudimentary horn pregnancy. 5

- Pseudopattern of an asymmetrical bicornuate uterus,

- Absent visual continuity between the cervical canal and the lumen of the pregnant horn, and

- The presence of myometrial tissue surrounding the gestational sac.

Additionally, hypervascularization typical to placenta accreta may support the diagnosis of rudimentary horn pregnancy. This feature can be diagnosed with colour 
flow Doppler and power Doppler sonography. The attachment of the rudimentary horn to the main uterus varies from a fibro-muscular band to an extensive fusion between the two horns where there is no external separation between them. The latter was the type of attachment found in the case of Madam CA. When the rudimentary horn pregnancy is small and facilities exist, it may be possible to resect it laparoscopically. ${ }^{5}$ Others have described the administration of methotrexate for termination of an early pregnancy in a rudimentary horn followed by elective laparoscopic resection. ${ }^{6}$

\section{CONCLUSION}

This case report has highlighted the need for high level of suspicion for this rare but very important complication of pregnancy.

Funding: No funding sources Conflict of interest: None declared Ethical approval: Not required

\section{REFERENCES}

1. Rackow BW, Arici A. Reproductive performance of women with mullerian anomalies. Curr Opin Obstet Gynecol. 2007;19(3):229-37.
2. Grimbizis GF, Camus M, Tarlatzis BC, Bontis JN, Devroey P. Clinical implications of uterine malformations and hysteroscopic treatment results. Hum Reprod Update. 2001;7:161-74.

3. Ural SH, Artal R. Third-trimester rudimentary horn pregnancy. A case report. J Reprod Med. 1998;37:919-21.

4. Nahum GG. Rudimentary uterine horn pregnancy. A case report on surviving twins delivered eight days apart. J Reprod Med. 1997;42:525-32.

5. Tsafrir A, Rojansky N, Sela HY, Gomori JM, Nadjari M. Rudimentary horn pregnancy: firsttrimester prerupture sonographic diagnosis and confirmation by magnetic resonance imaging. J Ultrasound Med. 2005;(2):219-23.

6. Edelman AB, Jensen JT, Lee DM, Nichols MD. Successful medical abortion of a Pregnancy within a noncommunicating rudimentary uterine horn. Am J Obstet Gynecol. 2003;189(3):886-7.

Cite this article as: Deora RK, Chawla P, Shetty NG. Pregnancy in non-communicating rudimentary horn. Int J Reprod Contracept Obstet Gynecol 2017;6:1691-3. 